\title{
Grammar Rules Matter: Should We Teach Inductively or Deductively?
}

\author{
Ganesh Bastola
}

\begin{abstract}
The main purpose of this paper is to analyze of Nepalese English language teachers perception of teaching grammar rules. This paper explores whether English teachers teach grammar inductively, deductively or using any other methods. It explores the arguments of teaching grammar rules based on teachers' perception and my experiences of teaching grammar. Teachers' perceptions were collected through a mini survey questionnaire. The study found that most of the respondents are in favor of deductive approach/method. A substantial majority of the respondents rated the relevance of GT method because it made learners learn theoretical and pedagogical components in easier manner. Most importantly, the majority valued its relevance abruptly considering a wide repertoire of methods, techniques, activities and resources. A small number of respondents perceived it to be somehow irrelevant and rated it low. In addition, this study reveals that teachers believe in deductive approach as the best way to teach grammar.
\end{abstract}

Key words: Grammar teaching, inductive, deductive, rules, perception

\section{Background}

Grammar is a set of rules people use when they speak or write any language. Giri (2007) opines that it refers to the way in which morphemes are put together into words, words into phrases, phrases into clauses and clauses into sentences (p. 9). Formally, it is the description of a language.

Language teaching, at every step, deals with the grammatical conventions that are to be coped with. Language teaching is a way of spreading the skills, abilities, and proficiencies in a language where grammar plays a crucial role. To quote Thornbury (1999), grammar teaching has always been one of the most controversial matters and least understood aspects of language teaching (p. ix). At different times during the long history of second language education, grammar has been regarded as a set of rules to be memorized. Today, grammar is still tested, taught and evaluated in this way in many parts of the world e.g. in the form of TOFEL, IELTS, etc. To achieve this objective, the paper sheds light on the present tendencies of learning and teaching grammar, its tenets and how grammar teaching is practiced for the development of proficiency of students. As a positive effect, teachers believe that learners have developed a strong grammatical proficiency since they need to know about the acceptability and unacceptability in terms of grammar use 
and usage. Giri (2007) states that grammar is reflected in native speaker's competence when they distinguish between acceptable and unacceptable sentences and it is possible only when they deserve the overall grammatical ideology (p.11). However, as a prescription of rules or description of the language as it is, grammar always has significance in second/foreign language pedagogy.

\section{Grammar rules and teaching English}

Developing confidence among learners in language skills is arguably the most important outcome of our teaching procedure. Adhikari (2012) states that from pedagogical perspective, communicative grammar should be given priority over other grammars, for it is not only about the rules of a language, but also about the rules of language use that takes into account sociolinguistic and discourse factors. Moreover, it treats grammar as a skill. The term 'language principles' refers to a body of the core essentials for understanding and manipulating one's language, and indeed, learning a foreign one and its grammar. Barbara (2007) states that scholars have set their own mark on the development of grammatical thought from a century. Philosophers such as Aristotle and Socrates realized the importance of grammar for all forms of language expression, particularly public speaking (rhetoric) and debate. I am closer to Celce-Murcia and Hilles (1998) who opine that grammar is a type of rulegoverned behavior. Grammar, then, is a subset of those rules which govern the configurations that morphology and syntax of a language assume. These rules are a part of what is 'known' automatically by all native speakers of a language; in fact, they do not exist outside of native speakers. A Roman, Marcus Varro, produced 25 volumes on the subject, translating the Greek and then applying the grammar to
Latin. Interest then spread around the world, with grammarians of other countries comparing the features of their languages with those of Latin. Slowly and gradually, its importance was realized and practiced accordingly all over the world to develop language skills on the part of ESL learners. A school in Kathmandu reputed for its quality of students' English did not teach grammar for more than 15 years to the learners in the language classroom (L. Gnawali, 6 January 2016, Personal communication). Later on, they realized that grammar was necessary on the part of learners and they adopted it. Now, the proficiency of our public school students is quite satisfactory in grammar. Adhikari (2012) states that grammar teaching should expose the students to the three different dimensions of language: form/structure, meaning and function. It means language teaching through Grammar Translation method has the pivotal role in language classroom in our Nepalese EFL context to make them aware of form/structure, meaning and function. However, we talk either CLT (Communicative Language Teaching) or TBLT (Task Based Language Teaching); but we practice GT method and deductive approach. Therefore, teaching English grammar and its rules have been essential to developing linguistic competence as well as performance on behalf of ESL/EFL (English as a Second/ Foreign Language) learners.

Language is a rule-governed phenomenon, in that it is totally regulated by its rules at various levels, i.e. phonological, morphological, syntactic, semantic and discourse. These linguistic rules constitute the grammar of a language. Therefore, grammar is the engine which drives language components together. Learning a language is a process of internalizing the grammatical rules of a language. Ellis (2006) states that second language grammar acquisition is a complex process;

$32 \quad$ Journal of NELTA, Vol 21 No. 1-2, $\quad$ December 2016 
and almost certainly it can be assisted best by a variety of approaches. But what is important is to recognize what options are available and what the theoretical rationales for these options are. Teaching and learning of any language are akin to teaching and learning of its grammar, which enables a learner to acquire the ability to produce and understand it's wellformed and appropriate sentences. However, the position of grammar in the teaching of foreign language has shifted dramatically in the last few decades. Giri (2007) states, "the history of foreign language teaching is a history of shifting attitude toward grammar' (p.9). The history of language teaching shows that grammar is the term of great antiquity that has been understood and defined differently over time. As a result of this, there has been a paradigm shift in teaching methodology.

With the emergence of various methods, approaches, techniques and ideologies such as Grammar Translation (GT), Direct Method, Audio-lingual Method, The Silent Way, Suggestopedia, Community Language Learning, Communicative Language Teaching (CLT), Task- Based Language Teaching (TBLT), Noam Chomsky's Universal Grammar (UG), and Krashen's Five Hypotheses (Larsen-Freeman \& Anderson, 2011), there have been drastic changes in the process of language learning and teaching. We have experienced newer knowledge about grammar learning and teaching. We have realized that there is not a single method as 'one fits all' in EFL/ESL context. Language teachers adopt various methods as per the demand of the content. The concept of post-method pedagogy gives an abundance of autonomy to the teacher, whereby they use appropriate methods as per the need of the content and necessity of the learners. Teachers seem to be aware of both the usefulness of methods and the need to go beyond them for successful teaching learning activities (Barbara, 2007). There was a great controversy between and among language scholars and grammarians. We find diverse thoughts, diverse grounded philosophies and underpinning principles they have developed about second language learners. Learning is something that happens automatically for many scholars and this is what it should be taught for others. Willis (2003) states that if we ask learners to listen and repeat a particular sentence, we are acting on the belief that such repetition is useful enough to justify the valuable classroom time it takes up, perhaps, the beliefs that it helps to rote learning which in turn promotes general language learning (p.1). In other words, some of the learners repeat the chunks and develop a conceptual framing very soon but another learner might take several attempts to understand the same concept. This indicates that teaching and learning of a language are the whole understanding of grammar rules principally. Teaching or learning a language without its grammar remains incomplete. We have experienced various procedures of teaching grammar explicitly or implicitly and deductively or inductively. Thornbury (1999) opines that grammar can be taught through a deductive approach since the teachers present the rules first, then teaching is followed by the examples in which the rule is applied (p. 29). Many grammarians advocate that grammar rules are to be taught to the learners directly and some of them oppose it. I am closer to the idea of Willis (2003) that if we give learners the grammatical rules or encourage them to discover the rules themselves, we are acting on the belief that rules make a valuable contribution to language description and that this kind of understanding helps promote learning (p.1). It is clear that rules need to be taught but indirectly. Grammar teaching either implicitly or explicitly is the matter of teaching and learning rules. As per my experience and understanding, in the context of ESL/EFL classrooms, 
elementary level learners cannot achieve those grammatical entities through context compared to the advanced level learners. Therefore, the major concern of this study is whether the beginner learners of English, in the Nepalese context, feel comfortable to practice grammar through rules or not.

\section{Issue statement}

In 2008, I appeared B.Ed. First- year examinations and started teaching, which was my stepping stone of teaching career. I started teaching in a private school, where medium of instruction was English.

At the beginning, teachers are typically less familiar with the subject matter, teaching method, teaching strategies, and teaching context, and lack adequate ways to plan and execute those (Richards \& Farrell, 2010); they need a lot of support and cooperation from the institution. Despite this fact, the Nepalese context is found different in the sense that novice teachers are rarely guided and they are never provided with support and cooperation. I also experienced similar situation when I started my career in 2008. Neither the school where I began my teaching career had a culture of providing induction and orientation to the novice teacher nor did I have such proficiency.

My students had severe problems regarding grammar in general and the use of preposition, article and so on, in particular. At the very beginning, I was totally disappointed since I was not confident enough. And I decided to read many grammar books to tackle my students' problem. Once one of my students in my grammar class asked me why they had to use an with umbrella but not with Europe? That made me shocked and disappointed. It was due to an insufficient knowledge of grammar and its rules since I never had an exposure to it. Nor my +2 level curricula had facilitated me about the grammar rules. Despite these facts, there were many things that would strike my mind such as second language acquisition and language teaching in general and grammar teaching i.e., grammar rules in particular. Burgess and Etherington (2002) conducted a research into teachers' attitudes to grammar and its teaching and learning. They found that the majority of teachers appreciated the value of grammar and had favorable attitude to Focus on Form. According to Thornbury (1999), the deductive approach is time saving in the sense that students do not go through the long stages of the inductive approach because the teacher presents the rule from the beginning. It is also time saving because the rule of form, for example, can be simply and quickly explained without trying to get them from examples. It also confirms many learners' expectations especially of those who do not like dealing with examples. I immediately made a kind of mini-research on the effectiveness of grammar teaching through rules on from students' perspective. I concluded that my students would learn no more, or they would progress no more until and unless I teach them grammar rules and their usage. I immensely experienced student's progress by teaching grammar rules.

Indeed, teaching grammar is one of the fundamental bases of our school and college curricula. After a few years of experience, I realized that learners are often confused with grammatical rules since grammar is prescribed from the elementary level in our context. The essence of grammar is felt necessary from the foundation level. For this, we can visualize the students' competence as well as performance which are not satisfactory. As a result, they fail to communicate among and between friends, colleagues and with the teacher in English. Moreover, they also 
fail to accomplish different types of proficiency test such as TOFEL, IELTS, and so on. Therefore, these situations compelled me to conclude that our learners have the problems in grammar rules. In my opinion, language teaching without grammatical convention makes no sense at all. Teaching grammar and its rules seem to be very much crucial. Grammar is necessary but not sufficient. Grammar does not only include its structure. Rather, it incorporates vocabulary and other aspects of language. To cope with these phenomena, one has to have sound knowledge of phonology, morphology, semantics and syntax. Therefore, grammar can serve its purpose. That is why we need to diagnose the students' problems and should provide enough exposure to grammar teaching and learning.

Thornbury (1991) states that grammar is partly the study of what forms are possible in a language. Traditionally, grammar has been concerned almost exclusively with analysis at sentence level. Thus, a grammar is a description of rules that govern how a language's sentences are formed (p.1).

According to Kirkpatrick (2012), grammar is a system of rules which gives guidance on joining words together in a meaningful way, thereby giving the language a structure.

Grammar is a core of language teaching. In Nepalese context, grammar rules along with context are to be promoted among learners, and that helps them to grow. Grammar is fundamental not only to facilitate the learners to produce fine literature but also to encourage them to write and develop creativity in their writing.
Thus, a language without grammar is like a bird without wings. The learner can easily notice acceptability and unacceptability of the language spoken to them if they have grammatical knowledge.

\section{Research purpose}

The main purpose of the study is to explore the perception and practices of English teacher towards teaching grammar rules.

\section{Research question}

This study is based on the following research question.

a. What are teacher's perceptions about teaching grammar rules?

\section{Methodology}

The core issue of this study was to analyze teacher's perception of teaching grammar rules. It is a kind of mini-survey research design where the primary sources of data were employed. A semi-structured openended interview questionnaire was prepared as the research tool to elicit the data for the study. Five English teachers teaching at the secondary level to higher secondary level were interviewed by asking five questions. The questions were grouped in a section and their responses were transcribed.

\section{Presentation of data}

The interviewed data were presented and analyzed using Seidel's (1998) model of data analysis. Seidel argued that qualitative data analysis is a process of 'noticing, collecting and thinking about an interesting thing' (1998, p.1). The respondents were grammar teachers teaching at higher secondary and secondary levels. Three of 
the respondents were from Higher Secondary level and two of them were from Secondary level.

\section{Analysis and interpretation}

To triangulate the data responses, their similar views were ranked in a hierarchy and distinct views were also given priority to enumerate the data received. The respondents' views were appreciated during the study to ensure confidentiality and I, as a researcher tried to analyze their views descriptively since the nature of the study was qualitative.

The method of teaching grammar was found similar. Only one grammar teacher was found to be teaching grammar inductively, and the rest followed the deductive approach. I noticed similarities and differences depending on the respondents' responses. The open-ended questionnaire was structured based on the research question that was to be addressed. All of the respondents responded in a similar way - saying that grammar for them was 'a set of rules'. Four respondents out of five agreed to be using 'deductive approach'. And only one out of five respondents said that he would employ inductive approach while teaching grammar. Regarding methodology, most of the respondents were found to have been using the deductive method. All of the respondents responded that they would present rules followed by examples. In a question about teaching, four out of five respondents responded that teaching grammar rules is a must in the Nepalese ESL context and they were found adopting the same method. Despite this fact, one of the respondents opposed it stating that he would never teach grammar rules deductively. Rather, he would teach inductively.
By the data elicited as aforementioned, I found that most of the English language teachers teach grammar rules in their language classrooms.

\section{Findings of the study}

After the study, the following findings are derived.

- Almost all the English language teachers teach grammar in their practical classroom deductively.

- Most of the respondents stated that they agreed on the notion of 'Grammar is a set of rules'.

- Most of the teachers of grammar in ESL context agreed to teach grammar deductively. To quote one of them (R1), "Our students have a very poor background of English, so they cannot derive the structure from the given sentences. Therefore, I often teach them deductively".

- The majority of the respondents were in favor of deductive approach/ method. Most of the respondents had the similar version. R2 said, "The students in the Nepalese EFL context love to practice along with the structure rather than examples".

- All of the respondents felt an essence of teaching grammar rules in ESL context. R3 said, "There won't be any problem to them if I provide the grammar rules to practice".

- The present study also showed that most grammar teachers adopt Grammar Translation (GT) method in their language classrooms. As R4 said, "I often start my grammar lesson with 
the rules even if they want the translation into Nepali".

- Thus, this study showed that teachers teach grammar deductively not because of the teacher's will but because of the students' desire.

- A substantial majority of the respondents rated the relevance of GT method because it made learners learn theoretical and pedagogical components in easier manner. Most importantly, the majority valued its relevance abruptly considering a wide repertoire of methods, techniques, activities and resources. A small number of respondents perceived it as somewhat irrelevant and rated it low.

\section{Conclusion}

Teaching of grammar rules facilitates second or foreign language learners. It enables learners to learn the language within a short span of time. The teachers of English, in the Nepalese ELT scenario, are fond of teaching grammar rules in their actual classrooms. I myself with seven years of teaching experience feel that teaching grammar deductively makes better sense than teaching it inductively. This is what has been proved by sampled perceptions of professional teachers as well. It is because they believe their learners feel it comfortable while learning the language.

And teachers also feel very comfortable in adopting deductive approach rather than inductive approach. Their belief is that the limited number of grammar rules enables the learners to generate unlimited number of sentences and they are able to monitor and correct their own performance themselves.
Thus, it can be concluded that teaching grammar via deductive approach is more practical, effective and meaningful on behalf of students. Therefore, our learners can be facilitated to learn grammar adopting deductive approach. This study revealed that approach is not a big deal; rather, the students' learning is.

Grammar provides a structured system for developing better linguistic competence, which helps to formulate a sound performance in second language learning. The systematic analysis and interpretation of a language is possible only if someone deserves and possesses a thorough knowledge of grammar. In such reality, grammar and its rule are inevitable in our context to develop all aspects of language from accuracy to fluency and from appropriateness to meaningfulness.

\section{References}

Adhikari, B.R. (2012). English grammar: Views of student teachers and communication of grammar to their students. A mini-research report submitted to University Grants Commission Sanothimi, Bhaktapur, Nepal.

Barbara. S. (2007). Grammar for everyone. Hillroad: CER Press.

Burgress, J. \& Etherington, S. (2002). Focus on grammatical form: Explicit or implicit? System, 30, 433-458.

Celce-Murcia, M \& Hilles, S. (1998). Techniques and resources in teaching grammar. New York: Oxford University Press.

Ellis, R. (2006). Current issues in the teaching of grammar: An SLA perspective. TESOL Quarterly, 40, 83107. 
Giri, A. (2007). Why teach grammar. Young Voices in ELT, 6, 9-12.

Kirkpatrick, B. (2012). Modern English grammar. United Kingdom: Media Light.

Larsen-Freeman, D. \& Anderson, M. (2011). Techniques and principles in language teaching.

Richards, J.C. \& Farrell, T.S.C. (2010). Professional developments for language teachers. Cambridge: Cambridge University Press.

Seidel, J. (1998). Qualitative data analysis: The ethnography. Retrieved from http:// www. engine. umich.edu/teaching/ crltengin/emgineering-educationresearch-resources/Seidel-qualitativedata-analysis.pdf

Thornbury, S. (1999). How to teach grammar. England: Pearson Longman.

Thornbury, S. (1991). Metaphors we work by. English Language Teaching Journal, 45, 193-200.http://dx.doi.org/10.1093/elt/ 45.3.193.

Willis, D. (2003). Rules, patterns and words: Grammar and lexis in English language teaching. Cambridge: Cambridge University Press.

The author: Ganesh Bastola is an M. Ed. graduate from Tribhuvan University. At present, he has been pursuing $M$. Phil. in ELE at Kathmandu University. He has about 10 years of teaching experience. Currently, Mr. Bastola has been teaching at Puspalal Memorial College, and Orchid International College, in Kathmandu.His areas of interest are translation, second language acquisition, professional development, and narrative inquiry.

\section{Appendix-1}

\section{A Survey Questionnaire - Teachers'Views on Teaching Grammar}

Dear Teachers

I am Ganesh Kumar Bastola. I teach the course "English Grammar" in secondary school. I am carrying out a mini research study under Kathmandu University, (especially in partial fulfillment of the course EDUC 514, Writing for Professionals For M Phil in English Language Education), investigating teacher's views on grammar and grammar teaching.

I'd like to request you to participate in my study by completing a survey questionnaire. The information you provide will be of great importance to shed light on ESL grammar teaching in the context of Nepal. I highly appreciate your cooperation. Your identity will not be stated in the report.

Name: Institute:

Level at which you are teaching:

1. What is grammar?

2. Which method do you prefer while teaching grammar?

3. Which method is appropriate in our Nepalese ESL/EFL context? 
4. How do you instruct your learnersdeductively? /in-deductively or any other method else?

$-------------------$

5. Are grammar rules to be taught to our students?

$-------------\cdots---$

6. Mention any two methods you prefer to use to teach grammar to your students.

i.

ii.

7. Mention any three resources you prefer to use to teach grammar to your students.

i.

ii.

iii.

8. Mention any three techniques you prefer to use to teach grammar to your students. ii.

iii.

The researcher can be reached atganeshkumar.gb@gmail.comif you wish to know more about the study.

I will send you the findings of this research if you are interested.

Thank you for your cooperation!

i. 